\title{
Sustaining the promise of the land-grant university system
}

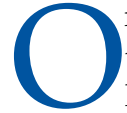
ne of the greatest inventions in the history of the United States, up there with the electric light bulb or the airplane or vaccines, was the land-grant university system.

In 1862, visionary leaders, despite the upheaval of the Civil War, saw that education, and specifically higher education, needed to be open and

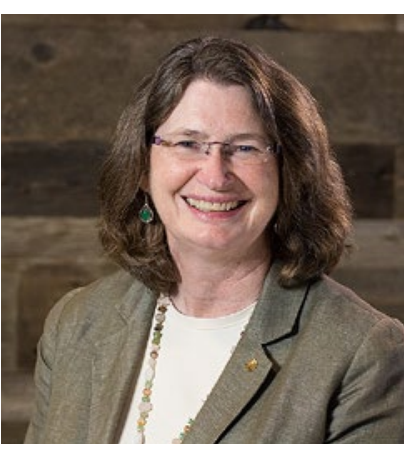

Barbara Allen Diaz

Vice President, Director of the Agricultural Experiment Station, Director of Cooperative Extension

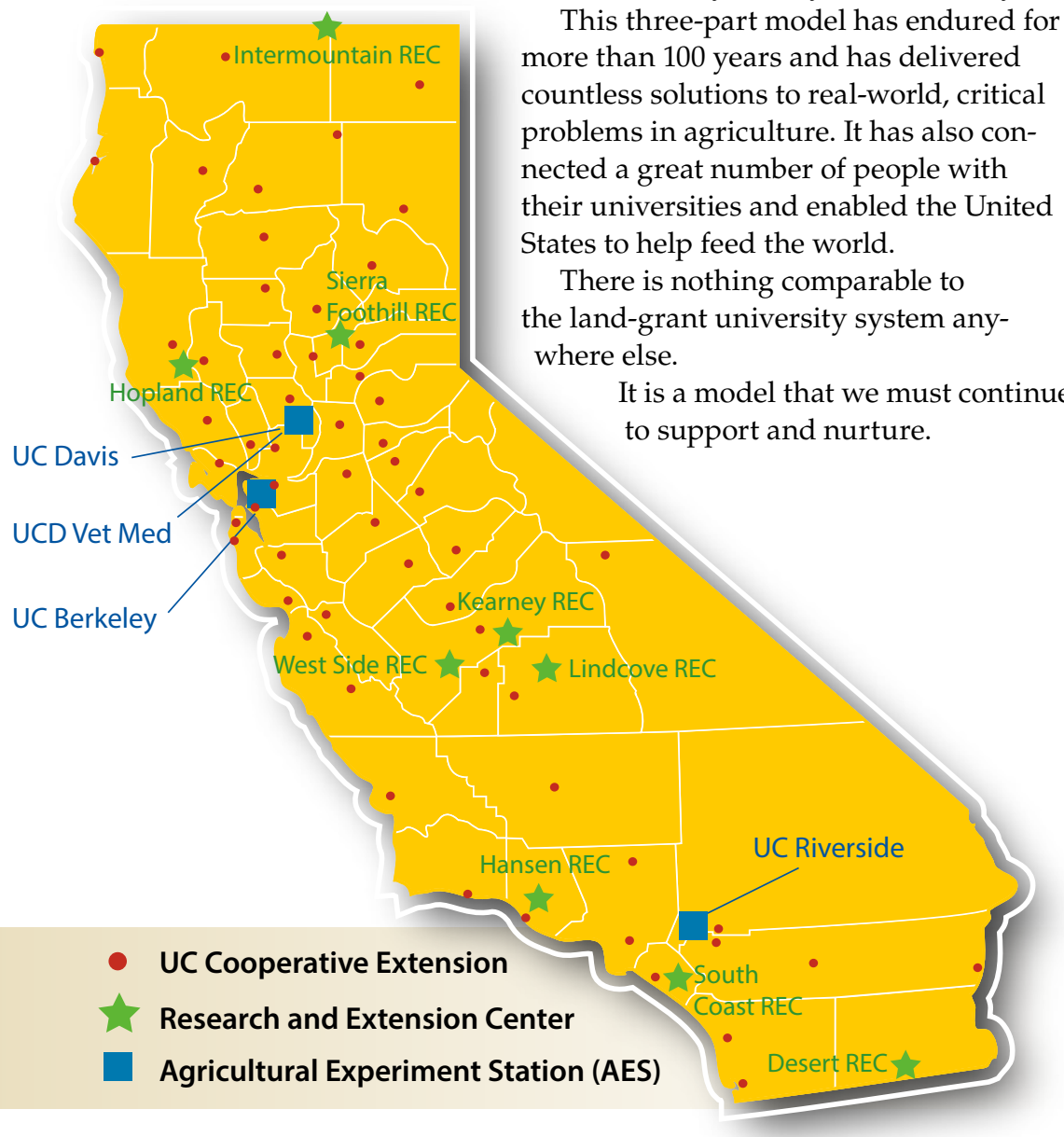

In California, the University of California is the land-grant university. The UC system includes 10 campuses from Davis to San Diego. The Agricultural Experiment Station includes programs on UC ANR's Research and Extension Centers and three campuses - UC Berkeley, UC Davis and UC Riverside - and includes faculty in the UC Berkeley College of Natural Resources; the School of Veterinary Medicine and the College of Agricultural and Environmental Sciences at UC Davis; and the UC Riverside College of Natural and Agricultural Sciences. UC ANR Cooperative Extension (UCCE) includes researchers, educators and other staff and is located in every county in California and at nine Research and Extension Centers and four campuses (UC Berkeley, UC Davis, UC Riverside and UC Merced). Together, these three complementary parts provide Californians with world-renowned research paired with local application of research and education programs, which test and deliver solutions to problems affecting communities and individual Californians throughout the state.

In California, the institution that ties together the three-part model - UC's land-grant mission, the AES and UCCE - is UC Agriculture and Natural Resources (UC ANR). It is a UC-wide organization with a specific mission to develop, coordinate and report on research and extension programs related to agricultural, natural and human resources. UC ANR provides programming based on research that helps ensure a safe, nutritious and secure food supply, healthy environments and thriving youth. The UC ANR Vice President - the position I have held since 2011 — is designated as the Director of AES and Director of UCCE on behalf of the UC system. UC ANR's system-wide mandate - with responsibilities spanning multiple program areas and the ability to engage partners on UC and California State University campuses, in public agencies and in the private sector - drives the division's activities and ensures that UC's agricultural and natural resources programs do not become overly focused on one campus or one geographic area.

UC ANR has four major sources of revenue: state revenue allocated to $\mathrm{UC}$; federal revenue based on various federal AES and CE-related acts; indirect cost recovery from contracts and grants and patent revenue generated by UCCE academics; and endowments and gifts. In addition, counties provide considerable in-kind support to county-based UCCE offices, and clientele such as grower associations provide substantial program support to individual UCCE researchers. UC campuses have similar revenue sources but also have tuition revenue, which supports an increasing fraction of their budgets. 
One of my top priorities as UC ANR Vice President has been to develop a stable funding model for UC ANR. We have made several gains. The UC ANR direct reporting line to the UC President has been restored, raising the division's profile within the UC system. We have hired 90 new UCCE academics and 45 more positions have been approved for recruitment; we are taking important steps to rebuild UCCE's capacity with a strategic focus on programs with strong demand and clear application to local needs. We have secured external salary support for six new UCCE advisor and specialist positions and also raised money for two endowed UCCE chairs, the first endowed chairs within UC ANR.

I believe that the UC ANR of the future will thrive. Cooperative Extension programs - which engage local communities and find solutions to local problems, often with worldwide applications - are more important than ever. As the world grows to 9 billion people, society's capacity to produce and distribute safe, nutritious and affordable food continues to depend on an understanding of multiple, interdependent factors. Soil is the foundation. Discovering and developing plant varieties resistant to drought, pests and diseases is critical. Research is ongoing to develop plant varieties that are nutritious, productive, salt tolerant and adaptable to climate change. Animal protein will continue to be grown from fiber produced on rangelands and finished with plant products to meet consumer demands for flavor, cost and sustainability. Developing and testing new plant varieties, integrated pest management techniques, plant and animal cultural practices, models for youth development, postharvest practices, irrigation and water conservation options and so much more is what great land-grant universities do.

The importance of feeding people, and of helping people to feed themselves, is currently well understood within UC. University of California President Janet Napolitano has launched the UC-wide Global Food Initiative (GFI), engaging faculty, centers, institutes, UCCE and the national laboratories. Individual campuses have created centers and institutes, like the World Food
Center at UC Davis and the Berkeley Food Institute at UC Berkeley. UC ANR is an active partner, and many of the division's ongoing efforts help to further the goals of the GFI: strategically locating CE advisors and specialists throughout the state where the need for expertise is greatest; and investing in AES campus partnerships to foster collaborations and coordination toward finding solutions to real-world problems, with science as the foundation for informed farm, community and policy decisions.

\section{Developing and testing new plant varieties, integrated pest management techniques, plant and animal cultural practices, models for youth development, postharvest practices, irrigation and water conservation options and so much more is what great land-grant universities do.}

Healthy environments, healthy food systems, healthy communities and healthy people in body and mind have been the goal since the founding of the three-part land-grant university system - the University, the AES and Cooperative Extension. A century of experience has proven the model's value, and it will remain relevant, providing affordable, accessible higher education for all; a focus on broad agricultural science to meet the needs of a growing nation and the growing world; and a mechanism by which our universities remain engaged with their most important constituents: the public. CA
Michael Yang, UCCE small farms and specialty crops Hmong agricultural assistant in Fresno County, checks a Hmong grower's Thai hot chili and luffa plantings, which must be covered in tunnels or hot caps.

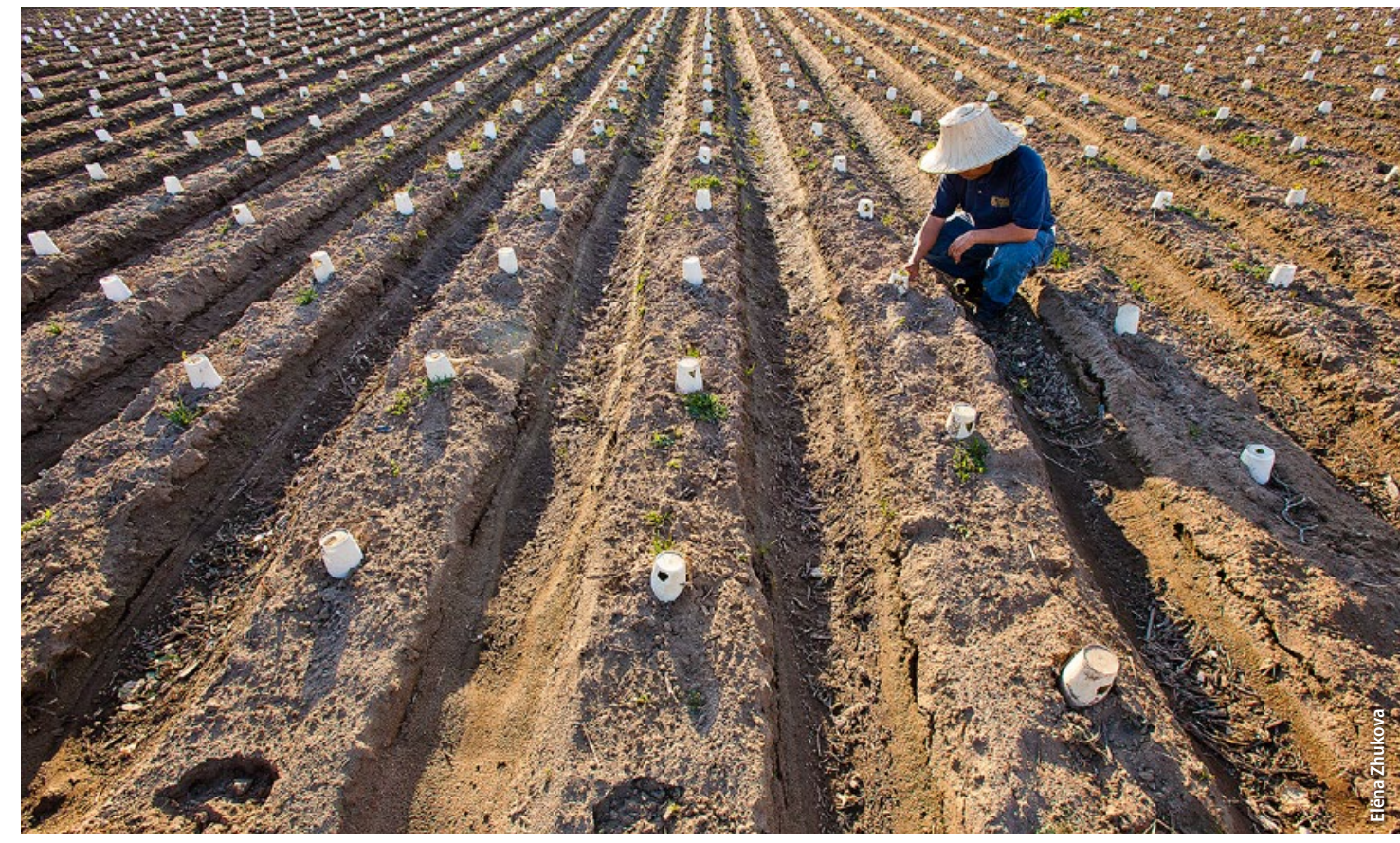

